SVU- International Journal of Veterinary Sciences, 4 (3): 70-79, 2021.

\title{
Bone exostosis lesions in distal limb of equines (17 cases; 10 horses, 7 donkeys): A clinical
} study

Mohammed A. Noby ${ }^{1}$, Abdel-Nasser A. Abdel-Hady ${ }^{1}$, Ahmed S. Soliman², Elhussein E. Mahmoud ${ }^{1 *}$

${ }^{1}$ Department of Surgery, Anesthesiology, and Radiation, Faculty of Veterinary Medicine, South Valley University, 83523 Qena, Egypt, ${ }^{2}$ Department of Surgery, Anesthesiology, and Radiation, Faculty of Veterinary Medicine, Cairo University, Cairo, Egypt.

\section{Abstract}

Lameness is an important clinical sign for the problems of locomotor system. When, visual inspection and diagnostic analgesia are not enough for reaching out the accurate diagnosis of the lesion, diagnostic imaging including radiology helps to determine the problem in a specific area. This study investigated the role of radiography as a crucial step for clinical diagnosis of bone exostosis lesions in equines. Between July 2019 and December 2020, seventeen animals were involved in this study 10 horses and 7 donkeys. These animals (age, $4.1 \pm 3.8$ years; weight, $199 \pm 98$ $\mathrm{Kg}$ ) were suffered from lameness with prominent bone exostosis on the distal limb, then were subjected to radiographic examination with lateromedial and dorsopalmar/dorsoplantar views. The most detected cases were more prevalent in the fore limb (76.5\%) than the hind limb (23.5\%). The most prevalent lesions recorded in this study were ring bone ( 9 cases; $52.9 \%$ ), Degenerative joint disease of the carpal joint and sore shins ( 3 cases; $17.64 \%$ ) for each, and then bone spavin and side bone were the lowest prevalent one ( 1 case; $5.88 \%$ ) for each. There was no treatment for all cases except sore shins which was improved thoroughly by topical iodine compounds with systemic administration of phenylbutazone. X-ray radiography is still beneficial for equine industry especially in the lesions related to the joints and bone exostosis that appeared on the distal limb.

Keywords:

Bone exostosis, Distal limb, Equines, Lameness, X-ray radiography

DOI: 10.21608/svu.2021.72294.1121 Received: April 13, 2021 Accepted: August 18, 2021

Published: September 8, 2021

*Corresponding Authors: Elhussein E. Mahmoud

E-mail: E.badry@vet.svu.edu.eg Citation: Noby et al., Bone exostosis lesions in distal limb of equines (17 cases; 10 horses, 7 donkeys): A clinical study. SVU-IJVS 2021, 4 (3): 70-79.

Copyright: (C) Noby et al. This is an open access article distributed under the terms of the creative common attribution license, which permits unrestricted use, distribution and reproduction in any medium provided the original author and source are created.

Competing interest: The authors have declared that no competing interest exists. 


\section{Introduction}

Lameness is considered the most important health problem affecting equines, and the main reason for decreased performance due to disturbance in the locomotor system in horses and donkeys (Hammarberg et al., 2016; Abdel-Hady et al., 2017; Himani et al., 2019).

Lameness can be commonly caused by trauma especially in the distal limb of equines (Fekadu et al., 2015). In between distal limb lesions causing lameness, bone exostosis which is defined as an abnormal bone growth inside the joints (Degenerative joint disease, DJD or osteoarthritis) and over the bones due to local periosteal reaction such as dorsal metacarpal disease (sore shins). The progressive degenerative disorder usually occurs in the front legs but can also be in the hind legs.

The accurate diagnosis of the nature and site of lesion causing lameness is very important as the first step of the treatment (Pfau et al., 2014), depending upon visual examination, palpation, nerve blocks, and finally diagnostic tools (Stashak, 2002). Although there are various recent diagnostic tools such computed tomography (CT), magnetic resonance imaging (MRI), and scintigraphy for assessment the hard tissues, but X-ray radiography still remains the standard diagnostic imaging technique for evaluation of bone exostosis in limbs because of easy accessibility, and low cost (Murray et al., 2004; Kinns and Nelson, 2010).

No report has been published previously presenting the bone exostosis lesions in the distal limb of equines collectively. Consequently, the objective of this study was to classify the bone exostosis lesions in the distal limb by using radiographic X-rays as a diagnostic tool, and to clarify their distribution among distal limbs of equines.

\section{Materials and methods}

This study was performed on 17 animals including 10 horses (6 males and 4 females) and 7 donkeys (4 males and 3 females) of different ages ranged from 6 months to 17 years (age, $4.1 \pm 3.8$ years; weight, $199 \pm 98 \mathrm{Kg}$ ). From July 2019 to December 2020, these animals were suffered from bone exostosis at different sites, which were admitted to Veterinary Teaching Hospital, Faculty of Veterinary Medicine, South Valley University, and Faculty of Veterinary Medicine, Cairo University, Egypt.

Firstly, complete case history was taken from the owner including onset, duration, and characters of lameness, previous medications or interference, and purpose of the animal. Close observation and examination of the animal at rest, on standing, and on motion to determine which limb was lame, then wooden hummer was used to detect pain response in the joint, followed by manipulation and passive flexion of the joint. Identification of the lameness degree was done according to lameness grading score system named American Association of Equine Practitioners (AAEP) (Ross, 2010).

Shimadzu radiographic device (Model: MD100P, SHIMADZU Corporation, Kyoto, Japan) (Hassaneen et al., 2020) and Collimax imaging apparatus (Model: R182, COLLIMAX Corporation, Tokyo, Japan) were used for radiographic 
examination of the cases at South Valley

University and Cairo University, respectively. Exposure factors for both devices were displayed (Table 1). For good interpretation, we used at least two radiographic views for the lesion mainly lateromedial (LM) and
Dorsopalmar/dorsoplantar (DP) views (Brokken et al., 2007), where x-ray tube was placed lateral to the foot in case of LM view, while in front of the distal limb in case of DP view. Radiographic films were assessed in consensus by at least two professors with $1^{\text {st }}$ author (M. A. Noby).

Table 1. Exposure factors for Equine limbs by Shimadzu radiographic imaging device (Model:

MD100P) and Collimax radiographic imaging device (Model: R-182).

\begin{tabular}{|c|c|c|c|c|c|}
\hline \multirow{2}{*}{ Structure } & \multirow{2}{*}{ Views } & \multicolumn{2}{|c|}{ Shimadzu } & \multicolumn{2}{c|}{ Collimax } \\
\cline { 3 - 6 } & & KV & MA/0.1S & KV & MA/S \\
\hline P3 & LM, DP & 75 & 10 & 64 & 320 \\
\hline Pastern & LM, DP & 75 & 10 & 64 & 320 \\
\hline Fetlock & LM & 65 & 10 & 58 & 320 \\
\hline Fetlock & DP & 70 & 10 & 62 & 320 \\
\hline Metacarpal \& carpal joint & LM, DP & 70 & 10 & 62 & 320 \\
\hline Metatarsal \& tarsal joint & LM, DP & 70 & 10 & 62 & 320 \\
\hline
\end{tabular}

P3: $3^{\text {rd }}$ phalanx LM: Lateromedial

DP: Dorsopalmar/Dorsoplantar

\section{Results}

\section{Degenerative joint disease:}

a. Carpal joint: it was recorded in three cases (2 donkeys and 1 horse) about $(17.64 \%)$. These cases were clinically characterized by angulation and painful swelling of the joint with severe lameness (Fig. 1A). Also, it is very hard to perform passive flexion and extension of the limb. Radiographic examination revealed more radiopaque intensity of the joint with absence of the joint spaces indicating presence of osteoarthritic changes with osteophytes formation especially in the dorsopalmar view (Fig. 1B and C). b. Tarsal joint: it was recorded in just one male horse $(5.88 \%)$ and named bone spavin. The owner complain that animal was suffered from hard swelling anteromedial at the level of the tarsal joint of the left hind limb (Fig. 2A), and lameness even after rest. With preliminary examination for older horse, lameness is very clear during trotting especially after applying spavin test. By radiography, osteoarthritic changes were evident in the tarsal joint with absence of spaces of intertarsal joints in lateromedial, dorsoplantar and oblique views (Fig. 2B and $\mathrm{C})$. 

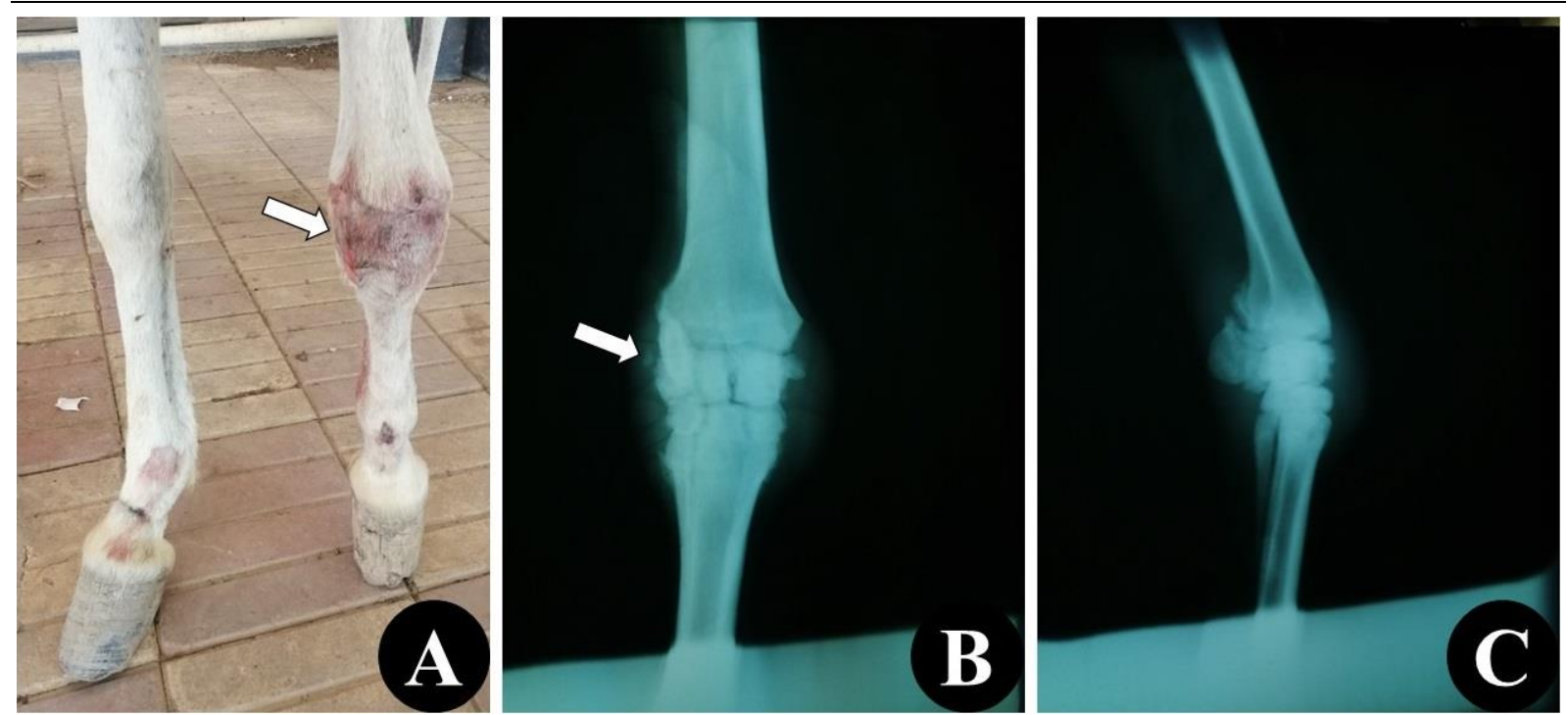

Fig. 1. Showing a 2.6-years-old female donkey suffered from swelling of the left carpal joint, with semi-flexion of the joint which was painful during passive extension of the limb (A). Dorsopalmar (B) and lateromedial $(\mathbf{C})$ views revealed severe osteoarthrological changes of the carpal joint with unclear joint space. Arrows indicated to the lesions.
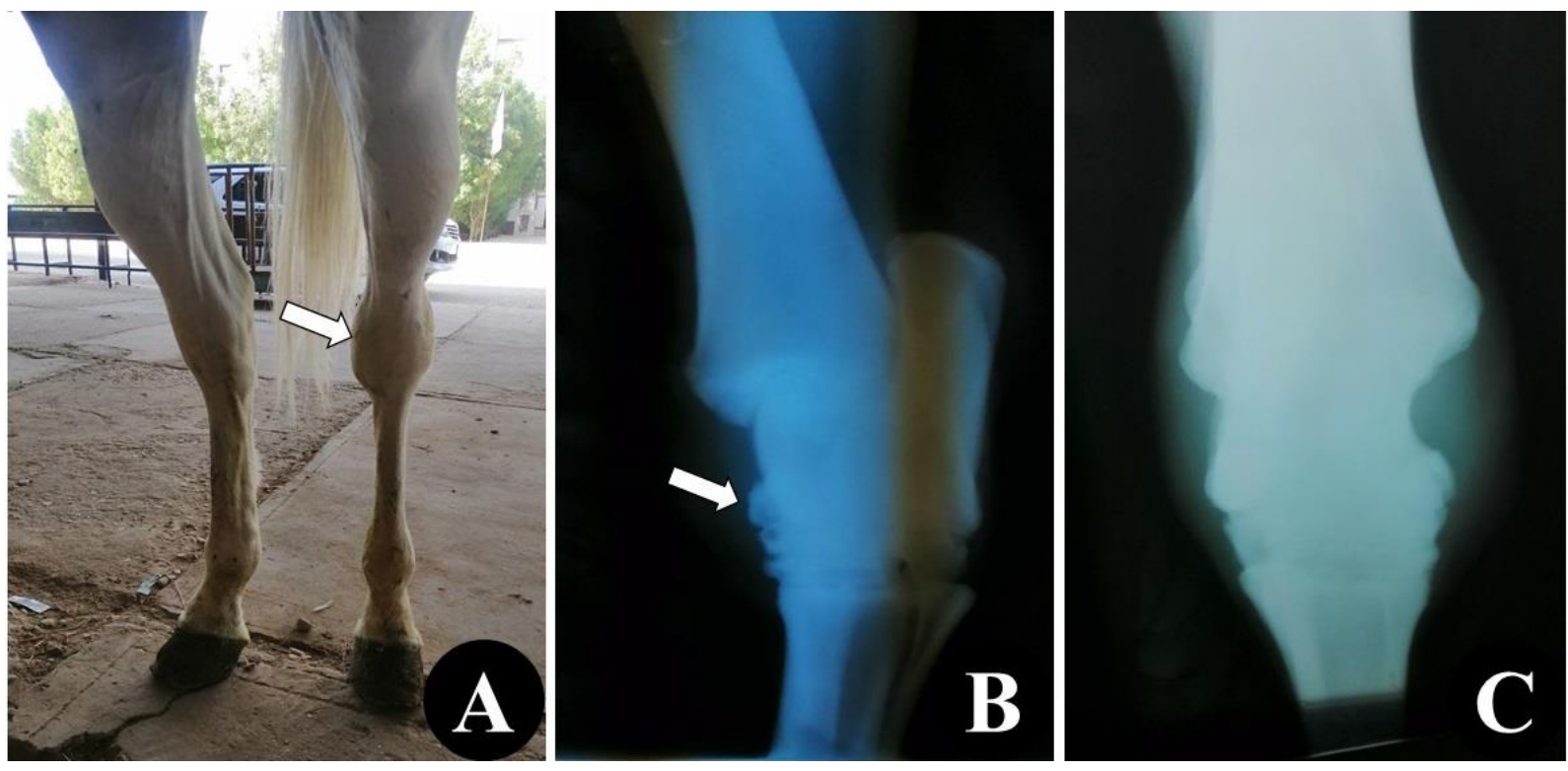

Fig. 2. Anteromedial swelling over the hock joint of the left limb of 17-years old male horse (A). Lateromedial (B) and dorsoplantar (C) views revealed severe osteoarthrological changes of the tarsal joint with absence of joint space. Arrows indicated to the lesions.

\section{Dorsal metacarpal disease (Sore Shin)}

It was recorded in 3 trained young horses only ( 1 male and 2 female) and represented $17.64 \%$. By physical examination, hard painful swelling over the dorsal aspect of third metacarpal bone can be easily detected without any evidence of lameness (Fig.
3A). For radiographic findings, lateromedial view is suitable for periosteal reaction over $3^{\text {rd }}$ metacarpal bone with newly bone layer formation (Fig. 3B). These cases were treated by systemic administration of NSAID with local rubbing using iodine 5\%, and completely recovered after 1 year (Fig. 3C). 

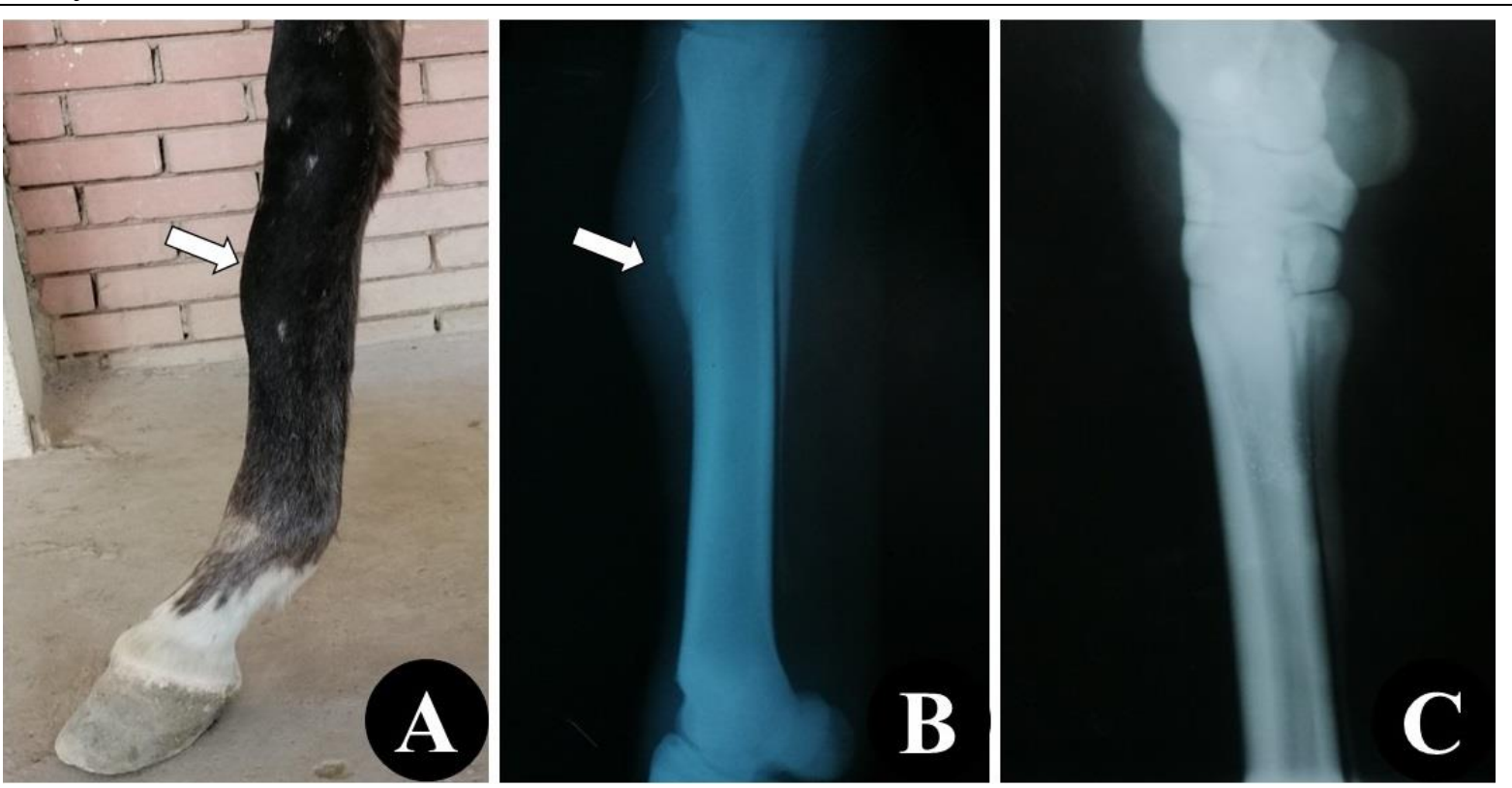

Fig. 3. Showing a 6-months-old male horse suffered from hard swelling on the dorsum of large metacarpal bone of the right fore limb (A). Lateromedial view for the large metacarpus of the young horse was showing presence of bony exostosis at the proximal third of the metacarpus (B). Complete recovery of the same case after 1 year $(\mathbf{C})$. Arrows indicated to the lesions.

\section{Osteoarthritis of the proximal interphalangeal joint and second phalanx (Ring bone):}

It was clinically observed periarticular in combination with high articular form in the proximal interphalangeal joint. It was the most prevalent lesion in the present study and was recorded about $52.9 \%$. It was detected in 5 donkeys (3 males and 2 females) and in 4 horses ( 2 males and 2 females). Six cases were detected in the fore limb and 3 cases in the hind limb. On clinical examination, equines were suffered from lameness which increased with weight bearing, pain during the passive flexion of the joint, and swelling over the pastern joint and second phalanx. On lateromedial view, bone exostosis was radiographically observed in the pastern joint and second phalanx, with absence of radiolucent area of the joint indicating clear narrowing of the joint space. While, radiographic density was decreased producing more radiopaque image on the dorsum of the second phalanx indicating presence of the bone exostosis (Fig. 4).

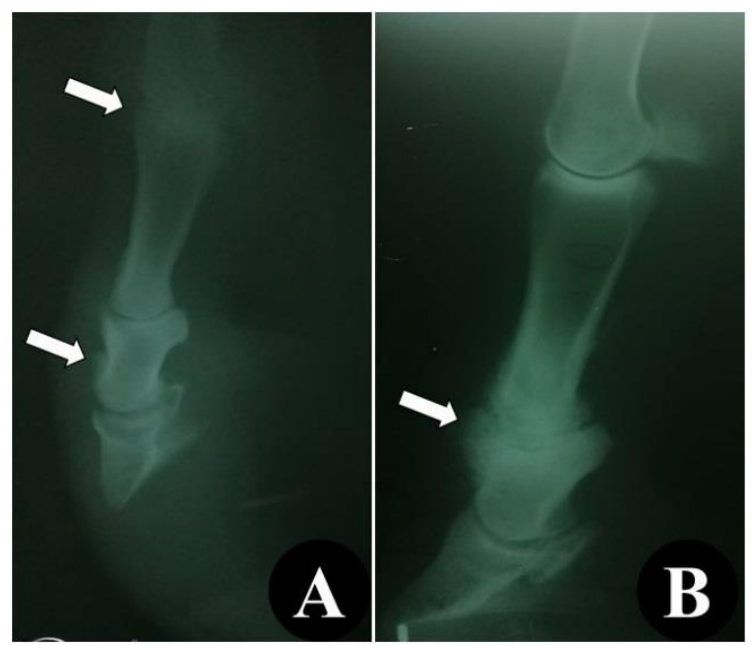

Fig. 4. Lateromedial views for different cases of articular bone exostosis (ring bone) in the metatarsophalangeal joint (A), and in the proximal interphalangeal joint (B). Arrows indicated to the lesions. 


\section{Side bone:}

It was recorded in one (2-years old) male horse with prevalence (5.88\%). During clinical examination, mild lameness was noticed, and ossification of the collateral cartilages over coronary band of the hoof on both sides during palpation. For easily radiographic diagnosis, it is beneficial to perform dorsopalmar view for confirming the ossification of collateral cartilages with radiopaque intensity (Fig. 5).

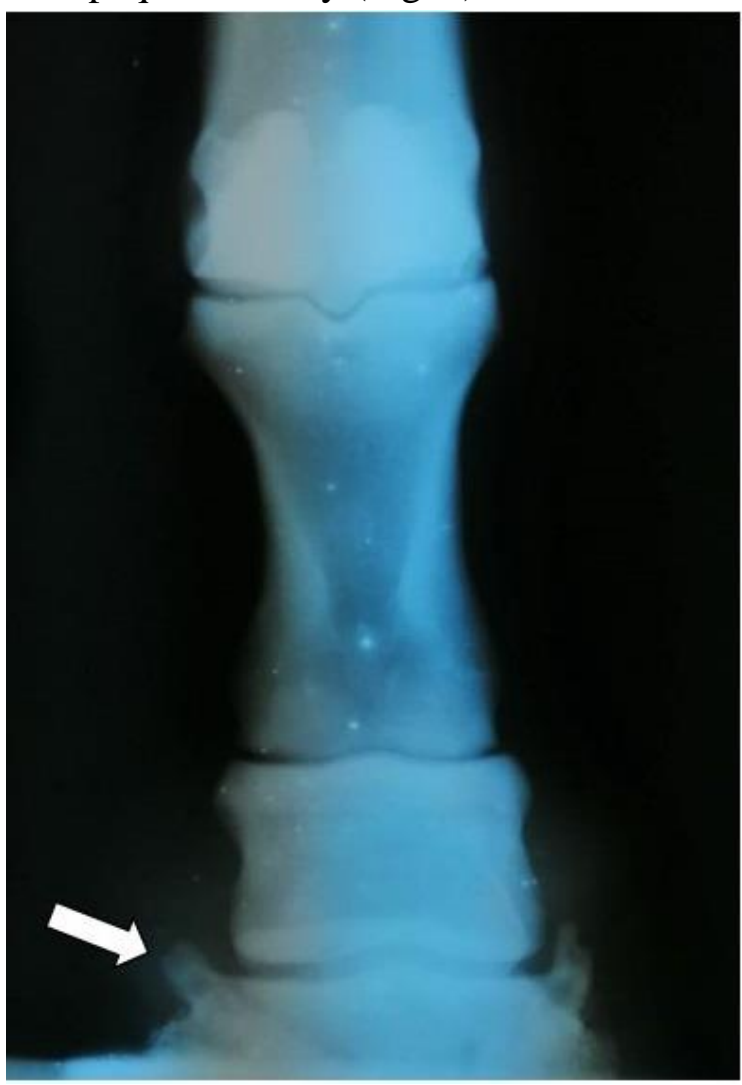

Fig. 5. Dorsopalmar view of a 2-years-old male horse showing ossification of collateral cartilage of the hoof of the fore limb. Arrow indicated to the lesion.

\section{Discussion}

It was the first study to investigate the description of radiographic examination for the bone exostosis lesions collectively at the distal limb as it encountered the common seat causing lameness in equine. Our study represented ring bone as the most prevalent

affection which was $52.9 \%$, then osteoarthritis of the carpal joint and sore shins was $17.64 \%$, and finally bone spavin and side bone was $5.88 \%$. Lameness is considered the most apparent clinical sign in case of musculoskeletal disorders. Subsequently, it is very important to evaluate degree of lameness. In the present study, we investigated that all cases with intraarticular bone exostosis were suffered from different degrees of lameness which especially were clearly appeared after flexion and extension of the joint during physical examination. While, most cases which were affected with extraarticular bone exostosis such sore shins were suffered from lameness and painful palpation, which was consistent with another study which reported that dorsal metacarpal disease (DMD) was characterized by severe lameness with painful palpation on the dorsum of the metacarpus (Buckingham et al., 1990; Nunamaker, 1991).

All cases of DJD in this study were easily diagnosed radiographically with evidence of narrowing joint space, osteophytes formation, and subchondral sclerosis, whereas other studies revealed that it is not conditionally all cases of DJD were easily to be diagnosed radiographically (Dyson and Ross, 2011); this is due to all cases which were involved in this study were in late stage of DJD. In addition, less than 5 years old horses did not show any radiographic signs for bone spavin (Eksell et al., 1998), at the same time, age of the animals which were suffered from DJD in the present study were 5-17 years. This study investigated that all cases which were affected with intraarticular bone exostosis were suffered from narrowing in joint space; 
which mean that loss of articular cartilage according to (Caron, 2011). Although, correlation between the clinical signs and radiographic findings was unmatched such as absence of radiographic lesions in the tarsal region with hock lameness (Verschooten and Schramme, 1994; Bathe, 2012).

This study indicated that most cases (10 cases) of the affected animals were males (4 donkeys, 6 horses), this is due to using of females in breeding purposes, while stallions were used for equestrian sports and drafting works. Also, we investigated that higher prevalence of bone exostosis in draft animals (12 animals; 7 donkeys, 5 horses) was noticed, this is due to exposure of draft animals to repetitive trauma which stimulates periosteal reaction with osteophytes formation at the area of phalanges and interphalangeal joint (Semika et al., 2012). Another explanation depends upon weather and nature of the work in Qena governorate, most of these animals which involved in this study were used in hard work especially in the sugar cane season on unpaved road leading to over stress on these working animals.

This study explained that forelimb (13 animals; 3 donkeys, 10 horses) was more commonly affected by bone exostosis than hind limb (4 animals; 2 donkeys, 2 horses), especially the cases of osteoarthritis of the proximal interphalangeal joint and second phalanx (ring bone) with the highest incidence in this study (52.9\%), although another study reported by Abdel-Hady et al. (2017) who revealed that periarticular ring bone was more frequent in the hind limb than fore limb. Unfortunately, most of the equine's owners didn't aware for the onset of these affections and didn't present the animal early for the treatment as the evidence of lameness may be subside shortly after trauma, then exaggeration will occur later on with subsequent bone exostosis.

Up till now, most treatment options for bone exostosis lesions are palliative just for temporary relief of the pain and to decrease severity of the inflammation with systemic administration of phenylbutazone and local application of iodine compounds which were similar with other studies (Timothy, 2008). In the last decades, stem cell therapy started to be a great promising option for musculoskeletal lesions because of easy accessibility from different sources such as bone marrow and adipose tissue (Mahmoud et al., 2016). Adipose derived stem cells achieved beneficiary effect on bone spavin with long term evaluation at 180 days in contrast to traditional steroids treatment which revealed transient good clinical outcome, but authors depend upon physical examination for lameness without using any diagnostic tools to confirm the complete absence of osteoarthrological reaction or not (Nicpoń et al., 2013). Osteophytes formation is considered one of the important feature of osteoarthritis, which was absent after multiple injections of bone marrow derived stem cells in a mature rabbit model when compared with single injection of stem cells which was not enough for disappearance of osteoarthritic changes (Mahmoud et al., 2019). In our study, there were 2 potential limitations: firstly; absence of treatment trials for different chronic cases. Secondly; small number of animals was involved in this study.

\section{Conclusion}

Early diagnosis and treatment of these affections should be done and raising the 
awareness should adapted for the care of equine limbs are recommended as long as any locomotor dysfunction appears by presenting their animals for veterinary investigations. Although development of the veterinary diagnostic tools such as MRI and $\mathrm{CT}$, it is still crucial to perform $\mathrm{x}$-ray radiography in the field of equine practice for diagnosis of musculoskeletal lesions. Till now, treatment of the bone exostosis lesions is unsatisfactory, and most veterinarians prefer to euthanize affected hopeless cases. So, extensive efforts in the further studies will focus on new biological therapeutics like platelet rich plasma (PRP) and mesenchymal stem cells (MSCs) especially for chronic joint lesions with radiographic description for the cases pre- and posttreatment.

\section{Conflict of interests}

All authors declare that there is no conflict of interests.

\section{Financial disclosures}

This work was not supported by any financial support.

\section{References}

Abdel-Hady AAA, Sadan MA, Metwally AA, Soliman AS (2017). Clinicoradiographic Studies on The Prevalent Distal Limb Affections in Working Equine at Luxor City. Journal of Advanced Veterinary Research, 7(1): 24-32.

Bathe AP (2012). Differentiating hook and suspensory pain. In Proceeding, Brimingham, United Kingdom.
Brokken MT, Schneider RK, Sampson SN, Tucker RL, Gavin PR, Ho CP (2007). Magnetic resonance imaging features of proximal metacarpal and metatarsal injuries in the horse. Veterinary Radiology \& Ultrasound, 48(6): 507-517.

Buckingham SHW, Jeffcott LB (1990). Shin soreness: a survey of Thoroughbred trainers and racetrack veterinarians. The Australian Equine Veterinarian, 8(4): 148-153.

Caron JP (2011). Osteoarthritis. In: Diagnosis and management of lameness in the horse, Ross MW, Dyson SJ, (2nd Ed.). Saunders, pp: 655-668.

Dyson SJ, Ross MW (2011). The Tarsus. In: Diagnosis and management of lameness in the horse, Ross MW, Dyson SJ, (2nd Ed.). Saunders, pp: 508-526.

Eksell P, Axelsson M, Broström H, Ronéus B, Häggström J, Carlsten J (1998). Prevalence and risk factors of bone spavin in Icelandic horses in Sweden: a radiographic field study. Acta Veterinaria Scandinavica, 39(3): 339348 .

Fekadu A, Teshome H, Worku T (2015). Epidemiology of lameness among cart pulling donkeys in Hawassa City Administration, Southern Ethiopia. Academic Journal of Animal Diseases, 4(2): 52-59.

Hammarberg $\mathrm{M}$, Egenvall A, Pfau T, Rhodin M (2016). Rater agreement of visual lameness assessment in horses 
during lungeing. Equine Veterinary

Journal, 48(1): 78-82.

Hassaneen ASA, Azab AA, Fouad IF, Noby MA, Mawas AS, Yousef NA (2020). Arthrogryposis Multiplex Congentia and Fetal Mummification in a Sheep with Hydrops of Fetal Membranes. Advances in Animal and Veterinary Sciences, 8(8): 848-852.

Himani H, Kumar A, Anand A, Singh N, Uppal V, Mohindroo J (2019). Clinical occurrence and radiographic diagnosis of distal limb lameness in equine. Indian Journal of Animal Sciences, 89(1): 15-24.

Kinns J, Nelson N (2010). Imaging tarsal trauma. Equine Veterinary Education, 22(6): 296-298.

Mahmoud EE, Adachi N, Mawas AS, Deie M, Ochi M (2019). Multiple intraarticular injections of allogeneic bone marrow-derived stem cells potentially improve knee lesions resulting from surgically induced osteoarthritis: An animal study. The bone and Joint Journal, 101-B: 824-831.

Mahmoud EE, Kamei G, Harada Y, Shimizu R, Kamei N, Adachi N, Ochi M (2016). Cell magnetic targeting system for repair of severe chronic osteochondral defect in a rabbit model. Cell Transplantation, 25(6): 1073-1083.

Murray RC, Dyson SJ, Weekes JS, Branch MV, Hladick S (2004). Nuclear scintigraphic evaluation of the distal tarsal region in normal horses.
Veterinary Radiology and

Ultrasound, 45(4): 345-351.

Nicpoń J, Marycz K, Grzesiak J (2013). Therapeutic effect of adipose-derived mesenchymal stem cell injection in horses suffering from bone spavin. Pol J Vet Sci, 16(4): 753-754.

Nunamaker DM, Butterweck DM, Black J (1991). In vitro comparison of Thoroughbred and Standardbred racehorses with regard to local fatigue failure of the third metacarpal bone. American Journal of Veterinary Research, 52(1): 97-100.

Pfau T, Spicer-Jenkins C, Smith RK, Bolt DM, Fiske-Jackson A, Witte TH (2014). Identifying optimal parameters for quantification of changes in pelvic movement symmetry as a response to diagnostic analgesia in the hindlimbs of horses. Equine Veterinary Journal, 46(6): 759-763.

Ross MW, Dyson SJ (2010). Diagnosis and Management of Lameness in the Horse. $2^{\text {nd }}$ Ed., Elsevier Health Sciences, St Louis. pp: 64-79.

Semieka MA, Sadan MA, Abdel-Hady AAA (2012). Traumatic Foot Fractures in Hard Working Donkeys. Journal of Advanced Veterinary Research, 2(4): 271-275.

Stashak TS (2002). The foot. In: Adams' Lameness in Horses. Lippincott Williams \& Wilkins: Philadelphia, pp: 645-733. 
Noby et al., 2021

SVU-IJVS, 4 (3): $70-79$

Timothy GE (2008). Overview of ringbone in horses. Bay Area Equestrian Network, pp: 45-51.

Verschooten F, Schramme M (1994).

Radiological examination of the tarsus. Equine Veterinary Education, 6(6): 323-332. 